\title{
Pregraduation clinical training program improves clinical competence of nurse students in Taiwan: An interventional study
}

\author{
Shwu-Ru Liou, Hsiu-Min Tsai, Ching-Yu Cheng \\ School of Nursing, Chang Gung University of Science and Technology, Chiayi Campus, Taiwan \\ Correspondence: Ching-Yu Cheng. Address: Chang Gung University of Science and Technology at Chia-Yi Campus 2 \\ Chiapu Rd. West Sec. Putz, Chiayi, Taiwan 613. Email: chingyuus@gmail.com.
}

Received: January 19, 2013

Accepted: March 20, 2013

Online Published: May 28, 2013

DOI : 10.5430/jnep.v4n1p1

URL: http://dx.doi.org/10.5430/jnep.v4n1p1

\begin{abstract}
Background: Recruiting and retaining new graduate nurses are high priorities for hospitals confronting nurse vacancy issues. However, new graduate nurses may not meet the professional entry-level expectations in providing safe patientcare skills. The purposes of this study were to evaluate the effectiveness of a nurse pregraduation clinical training program by measuring students' clinical competency levels, from the students' and the preceptors' perspectives, and by analyzing students' decision to continue working at the same hospital where they received their clinical practicum.

Methods: This study utilized a pretest-posttest design. In the developed training program, students practiced as a registered nurse under the supervision of a nurse preceptor for 208 hours. The Clinical Competence Questionnaire was used. The pregraduate participants $(\mathrm{N}=571)$ consisted of three cohorts of students who were completing their final semester of a $\mathrm{RN}$-to-BSN program. The preceptors $(\mathrm{N}=203)$ responsible for the students also completed questionnaires. Data were analyzed using descriptive statistics, Kolmogrov-Smirnov test, the Wilcoxon signed-rank test, and one-way ANOVA.

Results: Students significantly increased their clinical competence after completing the training program. The preceptors generally rated the students with a high clinical competence score; however, the preceptors' scores were lower than the students' self-rated scores. The students' satisfaction with their preceptors positively influenced their decision to remain working in the hospital or unit where they received the practicum.

Conclusion: New graduate nurses' transition in employment demands continuing support from the hospital, especially from preceptors who mentor them. To maintain the retention rate of nurses, hospitals are encouraged to offer a formal education program to preceptors regarding proper methods of mentoring pregraduates.
\end{abstract}

\section{Key words}

Pregraduation clinical training program, Clinical competence, Preceptorship

\section{I ntroduction}

The current nursing shortage is a serious healthcare issue on a global scale that requires an urgent resolution. Many healthcare facilities have prioritized both recruitment and retention of new graduate nurses as strategies to combat staff 
vacancy. According to an estimate released in 2004, the turnover rate of new graduate nurses in their first year of practice ranges as high as $36 \%$ to $60 \%{ }^{[1,2]}$. For most new graduate nurses, the first 3 months of employment is considered a critical period, and they generally terminate their employment within 90 days ${ }^{[3]}$. The most observed explanation for this phenomenon of short-term employment is that new graduate nurses often encounter difficulties in achieving an immediate and smooth transition from the school environment to the professional practice setting. Because staff turnover is an expensive loss, costing up to $\$ 82,000$ to $\$ 88,000$ per nurse ${ }^{[4]}$, it is important for healthcare administrators to understand that assisting new graduates in successfully transitioning to the professional practice setting can benefit staffing, reduce the turnover rate, increase the retention rate, and provide job satisfaction for these nurses ${ }^{[5]}$.

Nursing in the 21st century is a complex combination of the academic and the practical worlds that require effective integration ${ }^{[6]}$. Researchers and nurse educators emphasized that it was necessary to design a better organized approach of providing consistent and defined standards regarding competencies in practice settings to develop student nurses' competence before their graduation ${ }^{[7]}$. Therefore, senior capstone course that combines classroom learning and preceptorship in clinical is developed implemented in some schools in the United States. Although this course did not show effects on achievement exams or nursing license exam, new graduates often remained at their capstone sites or units or capstone specialty ${ }^{[8]}$. Other researchers proposed that, with the use of preceptorships, effective transition programs help to enhance nurse students' clinical comfort, confidence, and competency levels ${ }^{[9]}$. Collectively, these benefits are likely to improve pregraduate nurses' perception of their future working environment. Another study confirmed that additional competencies and knowledge designed in a clinical program that is beyond those obtained in the educational program are needed for a new graduate to successfully transition to the professional nurse role. In addition, most of the new graduates in the study were more willing to stay on with their residency program facility ${ }^{[10]}$.

Many studies have documented the benefits of well-designed nurse transition programs provided in Western countries to improve new graduates' clinical competence. In Taiwan, however, only a few nursing schools are capable of providing such programs, while others cannot due to insufficient financial budgets. Our serving school is one of the few that understands the worthiness of investing in and designing an appropriate program that enhances and promotes students' future competence in providing quality clinical patient care. Therefore, the purpose of this study was to strategically develop a pregraduation clinical training program conducted during student nurses' final semester to align their upcoming clinical practicum setting with their future work environment and to improve their clinical competence. Because we speculated that an increase in clinical competence might correlate to students' intention to remain in their job, we also surveyed students' willingness to continue working after graduation in the same hospital where they received their practicum. This study specifically addressed the following research questions: (a) What are the effects of the pregraduation clinical training program on pregraduates' clinical competence? (b) Is there a difference on pregraduates' clinical competence between the pregraduates' and the preceptors' perceptions? (c) What are the factors influencing pregraduates' willingness to remain working in the hospital or unit where they received their clinical practicum?

\section{Literature review}

Traditionally, nurse students acquire nursing knowledge and skills by attending classroom lectures and receiving supervised learning experiences in segmented time periods. However, these training methods may not adequately prepare new graduate nurses to perform skills at acceptable levels of competence in their first job after graduation ${ }^{[9,11]}$. Study results showed that only $35 \%$ of new graduate nurses could meet professional entry-level expectations at the time of their first employment, and only $25 \%$ of nurse leaders were fully satisfied with the new graduates' performance ${ }^{[12,13]}$. Similarly, a survey on nursing employers conducted by the National Council of State Boards of Nursing indicated that $57 \%$ of the respondents were not satisfied with new graduate nurses' ability in providing safe care practice ${ }^{[14]}$. Results from another study proposed that new nurse graduates felt incompetent in integration and application of knowledge and skills to provide quality and safety care ${ }^{[15]}$. Other researchers surveyed staff nurses and found that new nurses were ill prepared due to the lack of an adequate and appropriate transition program, both in length and in content ${ }^{[9]}$. Findings from various studies have indicated gaps and challenges in new graduate nurses' ability to transition to clinical practice during 
their first year of professional practice. Specific areas of insufficiency for these nurses include their inability to recognize patient problems, to prioritize and manage problems, to identify the rationale for patient problem-solving, and to communicate effectively with healthcare team members and patients ${ }^{[9,12]}$.

Many special programs have been developed in Western countries to meet the transition needs and help improve the clinical competence of new graduate nurses during their first year of employment. Although the content and effects of these programs vary widely, they share one common characteristic: The programs are conducted during the orientation period of the new graduates' first year of employment. A disadvantage of this scheduling approach is the inability of the new graduate nurses to handle the excessive amount of learning material and responsibilities of the real-world working environment to which they are not accustomed; consequently, they may be more likely to leave the position when they fail to meet the expectations of their new role as practicing nurses. Therefore, we proposed and developed a pregraduation clinical training program to improve the competency levels of upcoming graduate nurses before and after graduation. One of the key advantages of this program is that it integrates the academic world with the practical world of nursing, as proposed by Koh ${ }^{[6]}$. The program not only allows students to learn and become familiar with the clinical environment before they graduate, but also reduces the level of stress they will likely encounter when working and learning in their first practicing environment after they graduate. Furthermore, the program potentially connects student nurses to their first job, providing them the opportunity to continue working as professionals in the same healthcare facility and/or unit where they received their clinical practicum, thus reducing the amount of time and training they might need to adapt to their first employment setting.

Because the purpose of our study was to develop a pregraduation clinical training program conducted during student nurses' final semester to align their upcoming clinical practicum setting with their future work environment and to improve their clinical competence, we combined the Experiential Learning Theory, which was developed by Dewey and expanded more holistic by Kolb ${ }^{[16]}$, and the Situated Learning Theory, which was developed by Lave and Wenger ${ }^{[17]}$ to guide the study. According to Kolb, the Experiential Learning theory is "the process whereby knowledge is created through the transformation of experience. Knowledge results from the combination of grasping and transforming experience" ${ }^{[16]}$ (p. 41). This theory emphasizes how experiences, including cognitions, environmental factors, and emotions influence the learning process. It portrays two different modes of grasping experience: concrete experience and abstract conceptualization and two different modes of transforming experience: reflective observation and active experimentation. Kolb descirbed that the Experiential Learning Theory is a cycle of learning process starting from concrete experiences that is the basis for observations and reflections. These reflections are assimilated into abstract concepts from which new theories about the world can be drawn and actively tested. Through the testing of the ideas, individuals once again collect information through experience, cycling back to the beginning of the process. However, the theory proposed that each person must choose which learning mode will work best based upon the specific situation. Based on this theory, we developed the pregraduation clinical training program where students could gain clinical experience through the trainings in the real clinical world and reflected back to their basic knowledge and further collected more information and cycled back to the competence gaining process.

The Situated Learning Theory developed by Lave and Wenger ${ }^{[17]}$ proposed that much of what is learned is specific to the situation in which it is learned; that is, learning is situated, and knowledge needs to be presented in authentic contexts, settings, and situations that would normally involve knowledge. Furthermore, Gillespie and Paterson ${ }^{[18]}$ pointed out that the knowledge for clinical decision-making is grounded in concrete situations; students or nurses become competent or expert in their practice when they have sufficient experiences in the clinical setting where they can learn how to make decision by incorporating a broad knowledge and skills within the real complex environment. In addition, Lave and Wenger ${ }^{[17]}$ indicated that social interaction and collaboration are the essential components for situated learning, in that learners become involved in a "community of practice" where the embodiment of certain beliefs and behaviors can be acquired. As novices move from the periphery of the community of practice to its center, they inevitably become more engaged in and familiar with the explicit and implicit environment and, hence, they gradually assume the role of an expert. 
They may also realize that classroom-based learning activities are basically abstract knowledge and are out of context. Researchers proposed that only linking learning tightly to activities designed to improve one's performance, ideally in situations that allow "learning by doing" or experiential learning, can learners fully participate in the real world and generate meaning ${ }^{[19,20]}$.

Lave and Wenger ${ }^{[17]}$ examined the Situated Learning Theory under five different specialty settings. In all cases, the authors found that novices gradually acquired knowledge and skills as they learned from experts in the context of everyday activities. The authors also proposed that this theory is a good fit for competency-based training programs. In subsequent studies that empirically tested the Situated Learning Theory, findings presented strong and significant evidence in support of learning in the real environment. For example, one study examined the effects of situated learning on students' knowledge acquisition by comparing two groups of students using traditional and situated learning teaching strategies, and revealed that there is a significant correlation between situated learning and learners' performance ${ }^{[21]}$.

Using the Experiential Learning Theory and Situated Learning Theory as guidelines, we developed a program to enhance pregraduate nurses' competence in order to facilitate their eventual transition from the school setting to their future working environment. Our training program included a partnership approach: We invited hospitals to collaborate with our serving university not only to mutually understand both the hospitals' and university's needs but also to assist pregraduates in achieving required expectations for clinical competence. More importantly, we anticipated the possibility that, after graduation, the pregraduates who participated in the training program would continue working in the same facility where their training program took place, thus promoting the hospitals' successful recruitment and retention of new graduate nurses who are adequately prepared for the professional clinical setting.

\section{Methods}

\subsection{Description of the pregraduation clinical training program}

The purpose of the pregraduation clinical training program was to initiate a cooperative partnership between the nursing education institution and the healthcare facility to better assist pregraduates in achieving a smooth transition from the school setting to their future working environment. This program differed from traditional clinical programs or a school's typical clinical practicum in that students could choose a hospital to practice in which they might be interested to work for after graduation. The program also prolongs and advances the new nurse clinical orientation during the students' final semester while they are still attending school. In addition, the precetorship provides useful ways for students to learn positive nursing roles and to acquire socialization skills with healthcare team members and clients before graduation.

The pregraduation clinical training program is a 3-credit-hour required course that students must take to fulfill their graduation criteria. It is designed as a clinical competence-oriented course containing 208 hours of practice during a 6-week period and is conducted at the clinical site to bridge the gap between students and their nurse roles. Students are given the option of choosing a specialty or a hospital in which they have an interest to practice. In order to ensure the program was implemented properly and to allow students as many choices as possible, we interviewed officials at all the hospitals that had passed an evaluation by the Department of Health in Taiwan and were qualified as a teaching hospital for practicing students. We also discussed the content of the program with the hospitals' nursing administers. A total of 17 hospitals were qualified and willing to participate in our program. The program emphasizes both real-situated and hands-on experiences, and it asks hospitals to provide opportunities for students not only to perform independent clinical skills but also to attend new employee training programs and in-service educational classes. There was a merger of an academic capstone experience with a real-world orientation program.

Our pregraduation training program also recognizes the importance of preceptors in shaping students' nursing viewpoints and career goals. Thus, we purposely assigned no more than two preceptors to each student, and the preceptors were 
required to provide each student with consistent guidance and support. Because preceptors are registered nurses who have passed a preceptor training program administered by the healthcare facility or are level three nurses (expert nurses) in that facility and qualified as a preceptor, we reasoned that preceptors would be suitable role models in guiding students with their enthusiasm for the nursing profession. This arrangement was different from traditional clinical practicum where students were instructed by clinical instructors or nurse preceptors who might not receive any preceptor training.

Before the pregraduation training program officially started, students were first requested to practice their technical skills by viewing a series of video-recorded skills in video-on-demand format and, later, to practice those skills in skill labs. During the training program, students were asked to work the same schedule with their assigned preceptor and with at least two different kinds of schedules, which might be a combination of day, evening, night, 8-hour, or 12-hour shifts. In addition, school faculty members made arrangements to assist student nurses' clinical learning and to coordinate the program between the school and the clinical facility. Our program also incorporated a 4-hour, biweekly roundtable discussion between students and their faculty members. These roundtable discussions were added to serve as communication channels between students and faculty and to provide students the opportunity to share their experiences.

\subsection{Design and participants}

We utilized a pretest-posttest research design with a convenience sample for our study. Three cohorts of students in their final semester of a 2-year RN-to-BSN day school program were invited to participate in this pretest and posttest study conducted from 2009 to 2011 (three cohort years). All of the 571 participating students had previously graduated from a 5-year nursing diploma program and were full-time students without any clinical nursing experiences. A total of 194 (cohort year 2009), 199 (cohort year 2010), and 178 (cohort year 2011) students completed both the pretest and the posttest, with a response rate of $94.2 \%, 92.6 \%$, and $90.4 \%$, respectively. Each student's assigned preceptor was also invited to complete questionnaires in order to evaluate the clinical competence of the students she or he directed. A total of 203 (cohort year 2009), 203 (cohort year 2010), and 154 (cohort year 2011) preceptors completed and returned the questionnaires, with a response rate of $98.5 \%, 94.4 \%$, and $78.2 \%$, respectively.

Of the 571 participating nursing students, only three were male. Students in all three cohorts did not differ in work shifts, length of work shifts, and number of patients they cared for. However, students in the 2011 cohort year $(\mathrm{M} \pm \mathrm{SD}=21.74 \pm$ .67) were significantly younger than students in the $2009(\mathrm{M} \pm \mathrm{SD}=22.14 \pm .92)$ and 2010 cohort years $(\mathrm{M} \pm \mathrm{SD}=22.22$ $\pm .97, \mathrm{~F}=15.67, p<.001)$.

\subsection{Instruments}

We developed the Clinical Competence Questionnaire (CCQ) based on literature reviews ${ }^{[9,22-24]}$ and on a focus group that was conducted to measure nursing clinical competence. The CCQ contains 47 items with a 5-point Likert scale ranging from 1 ("do not have a clue") to 5 ("know in theory, competent in practice without any supervision"). A higher score indicates a higher level of nursing competence. The validity of the scale was tested and confirmed by content validity, concurrent validity, and factor analysis. The content validity index was 1.0. Factor analysis showed that the CCQ could explain $70.8 \%$ of the variation of clinical competence with two major factors: competency in nursing professional behaviors (explained $59.6 \%$ of the variation) and competency in nursing skills (explained $70.72 \%$ of the variation). Reliability was tested by Cronbach's alpha and the result was .97 for the entire 47-item CCQ in the scale development study. In this current study, the Cronbach's alpha for the entire CCQ was .98 for students and .96 for preceptors.

In addition to the CCQ, we asked students to rate their degree of satisfaction with their own performance, with the pregaduation clinical training program, and with their preceptors (ranging from $1=$ very dissatisfied to $5=$ very satisfied). They were also asked to respond about their willingness (from $0 \%$ to $100 \%$ ) to continue working in the hospital or unit where they received their clinical practicum. The assigned preceptors were asked to rate their level of satisfaction of the performance of students they instructed (ranging from $1=$ very dissatisfied to $5=$ very satisfied). 


\subsection{Data collection}

Data were collected using a self-report questionnaire that students completed at the beginning and the end of the pregraduation clinical training program. The time for a student to complete a questionnaire was about 10 minutes. The questionnaire included demographic items and a scale measuring clinical competence. Each student received a copy of the questionnaire and a self-addressed-and-stamped envelope at pretest and posttest. When the program was completed, the preceptors received the same set of materials to evaluate their assigned student's competence from the preceptors' perspective.

\subsection{Ethical consideration}

The proposal was reviewed and approved by the local Institutional Review Board (IRB) in Taiwan. Before the pregraduation clinical training program started, the purpose and procedure of the program and the study were explained verbally to students in class. The questionnaire, along with a cover letter describing the purpose and procedures of the study and the participants' rights and confidentiality, were provided to students before the beginning of the program. Students were assured that they had the right not to answer questions, even the entire questionnaire, that they did not feel comfortable with. However, all students were required to attend the program because it was a requisite course for graduation. Students were told that their pre- and post-test questionnaires would be matched based on an assigned number; however, they did not know their preceptor would fill out questionnaires that related to them. This blindness prevented the students from trying to please their preceptor. However, students did know that their preceptor would grade their clinical performance. The questionnaire and a cover letter that described the same aforementioned content were also sent to the preceptors at the end of the training program. Participants were told not to put their name on the questionnaire. Instead, each participant was randomly assigned a number and the number was hid in the footnote that showed the name of the study. No information that could identify the participant was listed in the questionnaires. Questionnaires were handed to each student by the research assistant and were mailed to each preceptor individually by mail. Participants were not asked to sign a consent form; however, returning a completed questionnaire indicated participants' agreement to participate in this study. Completed paper questionnaires were stored in a locked place accessible only to the investigator. An information sheet that contained the participants' names and their assigned number was created and stored in a locked cabinet. Only the primary investigator and the research assistant had the access to the locked cabinet. The information sheet was shredded after all data were collected. Data were matched based on the participants' assigned number and were managed and analyzed anonymously and confidentially. The results of the study are presented as group data rather than as an individuals' information.

\subsection{Data analysis}

The data were managed and analyzed using SPSS 15.0. Descriptive statistics were used to examine demographic information and level of clinical competence. Measured variables were examined for their normality before conducting inferential statistics. The Kolmogrov-Smirnov test showed that the students' competence at pretest and posttest and the preceptor-rated students' competence were not normally distributed. Therefore, the Wilcoxon signed-rank test was applied to examine the difference on clinical competence between paired student and preceptor. One-way ANOVA, which is not affected by non-normality ${ }^{[25]}$, was used to compare differences of major measured variables among various demographic groups. Two-tailed tests and alpha level of .05 were used to determine statistical significance.

Students in the three separate cohort years did not differ in their clinical shifts (only one shift, two rotated shifts, and three rotated shifts) and in the number of patients they cared for. Fewer students in the 2011 cohort year (40.6\%) practiced nursing skills before the clinical practicum than did students in the $2009(63.8 \%)$ and $2010(61.6 \%)$ cohort years $\left(\chi^{2}=\right.$ $22.62, p<.001)$. However, because students who did or did not practice skills before the clinical practicum did not differ in their general clinical competence and dimensions of competence, the data of students in all three cohorts were combined in statistical analyses. 


\section{Results}

\subsection{Clinical competence and willingness to stay}

Most students in cohort year 2009 (63.8\%), cohort year 2010 (61.6\%), and cohort year 2011 (40.6\%) practiced nursing skills before their clinical practicum. In general, students were satisfied with their clinical performance $(\mathrm{M}=3.53, \mathrm{SD}=$ $.66)$ and with their preceptors $(\mathrm{M}=4.18, \mathrm{SD}=.75)$. Similarly, preceptors were satisfied with the performance of students they instructed $(\mathrm{M}=3.95, \mathrm{SD}=.63)$. The students and the preceptors were all satisfied with the pregraduation clinical training program $(\mathrm{M}=3.72, \mathrm{SD}=.59$ and $\mathrm{M}=3.63, \mathrm{SD}=.63$, respectively). Students exhibited a $60.48 \%$ probability (range $0 \%-100 \%$, median $=60 \%$ ) of being willing to continue working in the hospital where they received their clinical practicum and a $50.49 \%$ probability (range $0-100 \%$, median $=50 \%$ ) of being willing to continue working in the unit where they received their last clinical training program.

\subsection{Effects of the pregraduation clinical training program on students' clinical competence in pregraduates' and preceptors' perspectives}

Students perceived a high level of their clinical competence both before and after completing the pregraduation clinical training program (see Table 1). Preceptors also perceived high levels of their assigned students' clinical competence after completing the program. However, students had significantly higher scores on the CCQ and on all of its subscales than the preceptors who rated them. After the clinical training program, students perceived an increase in their global clinical competence and, specifically, in their professional behaviors competence and their core skills competence (see Table 1).

Table 1. Comparisons of Pregraduate Nursing Students' Pretest and Posttest Clinical Competence and Preceptor-rated Student Competence

\begin{tabular}{|c|c|c|c|c|c|c|c|}
\hline & \multirow{2}{*}{$\begin{array}{l}\text { Pretest for } \\
\text { students }\end{array}$} & \multirow{2}{*}{$\begin{array}{l}\text { Posttest for } \\
\text { students }\end{array}$} & \multirow{2}{*}{$\begin{array}{l}\text { Posttest for } \\
\text { preceptor }\end{array}$} & \multicolumn{2}{|c|}{ Pre-post students } & \multicolumn{2}{|c|}{ Post student-preceptor } \\
\hline & & & & $Z$ & $\boldsymbol{P}$ & $Z$ & $\boldsymbol{P}$ \\
\hline $\begin{array}{l}\text { Clinical } \\
\text { competence }\end{array}$ & $190.43 \pm 25.69$ & $195.23 \pm 21.94$ & $177.94 \pm 27.46$ & 4.00 & $<.001$ & -12.13 & $<.001$ \\
\hline $\begin{array}{l}\text { Professional } \\
\text { behaviors }\end{array}$ & $67.65 \pm 9.24$ & $68.99 \pm 8.20$ & $62.13 \pm 3.73$ & 3.01 & .003 & -12.59 & $<.001$ \\
\hline $\begin{array}{l}\text { General } \\
\text { performance }\end{array}$ & $51.81 \pm 7.66$ & $52.24 \pm 6.58$ & $48.64 \pm 7.79$ & 1.01 & .31 & -9.36 & $<.001$ \\
\hline Core skills & $49.57 \pm 7.77$ & $52.06 \pm 7.04$ & $46.65 \pm 8.29$ & 6.80 & $<.001$ & -12.50 & $<.001$ \\
\hline Advanced skills & $21.30 \pm 4.10$ & $21.68 \pm 3.73$ & $20.34 \pm 4.18$ & 1.99 & .05 & -6.15 & $<.001$ \\
\hline
\end{tabular}

\subsection{Factors influencing students' willingness to remain working in the hospital or unit where they received the program}

Students who were not satisfied with their preceptor and students who were neither satisfied nor dissatisfied with their preceptor had a lower level of willingness to remain working in the unit where they received their practicum than students who were satisfied or very satisfied with their preceptor $(\mathrm{F}=6.25, p<.001)$. However, the level of students' satisfaction with their preceptor did not differ from the level of their willingness to remain working in the hospital where they received their practicum $(\mathrm{F}=1.36, p=.25)$. Students who were very satisfied with the pregraduation clinical training program had a higher level of willingness to remain working in the hospital than students who were not satisfied with the program and students who were neither satisfied nor dissatisfied with the program $(\mathrm{F}=5.28, p<.001)$. Students who were very satisfied with the program had a higher level of willingness to remain working in the unit where they received their practicum than students who were very dissatisfied, not dissatisfied, or neither satisfied nor dissatisfied with the program $(\mathrm{F}=5.72, p<$ .001). However, the level of students' willingness to remain working in the hospital or unit where they received their clinical practicum was not related to their perceived clinical competence $(r=.001$ and $r=.02$, respectively). The level of 
students' perception of their clinical competence did not differ by the degree of their satisfaction with the program $(\mathrm{F}=$ $.14, p=.93)$ or with their preceptor $(\mathrm{F}=.96, p=.41)$.

\section{Discussion}

\subsection{Discussion of the results}

Study findings revealed that, in general, the pregraduation clinical training program had a significant effect on promoting students' clinical competence, especially competence in nursing professional behaviors and core nursing skills. The result is consistent with the Situated Learning Theory ${ }^{[17]}$, which proposes that learning is situated, that knowledge needs to be presented in authentic contexts and situations that would normally involve that knowledge, and that instruction must take place in complex, social environments. This result also supports one of our purposes of designing the pregraduation clinical training program.

In previous studies, researchers found that nursing students might display overcompetence in their performance ${ }^{[26,27]}$. A study analyzing a 10-year longitudinal database on a residency program for registered nurses found that observers rated lower on the competency of nurses than the nurses rated themselves ${ }^{[28]}$. Similarly, our study results revealed that not only the students rated high on their perception of their clinical competence but also the preceptors rated high on their perception of the students' competence, although the score rated by the students was significantly higher than the score rated by the preceptors. However, surprisingly, the preceptors rated high on their perception of the pregraduates' clinical competence, a finding that differs from previous study results. For example, in a study that surveyed 57,000 nurse leaders, only $25 \%$ of the leaders were fully satisfied with new graduates' performance ${ }^{[13]}$. Other researchers have reported that a profound gap in clinical performance expectations exists between new graduates and healthcare staff in clinical settings ${ }^{[29,30]}$. Based on the results of our study, the implementation of the pregraduation clinical training program might shorten the gap between students' competence and preceptors' expectations on students' performance.

Another important purpose of the pregraduation clinical training program is to provide students the opportunity to practice in the same environment where they might choose to work after graduation. Through this arrangement, new graduates might be more willing to remain working in the facility where they received their practicum. They might also be better prepared to adapt to the work environment because of their experience in and familiarity with the same setting where they learned to practice as students. An exciting finding was that $60.48 \%$ of students were willing to work for the same hospital and $50.49 \%$ were willing to work in the same unit where they chose to practice for the pregraduation clinical training program. This result is consistent with other researchers' findings ${ }^{[10]}$.

However, another finding in our study indicated that nursing students might be unwilling to work in the same hospital or unit after graduation if they perceive a poor relationship with their preceptor during the practicum. The students believed their preceptor would become their future colleague if they chose to remain working in the same facility after graduation. If the students did not feel comfortable or confident with their preceptor, they reported they would likely choose either not to work in the same facility or to leave after a short period of employment. The pregraduates' concern is understandable. A significant indicator that affects nursing students' willingness to remain working in the same facility where they received their practicum is the students' degree of satisfaction with an individual preceptor and with collegial relationships ${ }^{[2,31]}$. Unfortunately, many new graduate nurses report receiving a lack of acceptance, respect, positive support, and positive verbal feedback from their preceptors. In addition, because new graduates fear retribution, they are reluctant to report poor treatment from preceptors ${ }^{[32]}$. Findings from other qualitative studies indicate that many new graduate nurses have difficulty in building relationships or communicating with experienced nurses, or they encounter unhappy nurses or other personnel, which can impede their successful transition from the academic setting to professional practice ${ }^{[31,33]}$. 
The pregraduation clinical training program implemented in our study helped pregraduate students determine whether the work environment where they received their practicum suited their nursing skills and intended career path after graduation. If students liked and adjusted well to the environment, they were willing to work for the same hospital or unit where they received their practicum. If they were unable to adjust to the environment, they learned they could choose another facility that might be more in alignment with their skills and future goals. In both cases, the participating hospitals in the pregraduation clinical training program would likely benefit. For students who might potentially choose to work in the same hospital or unit after graduation, the facility would not have to spend extra time and funds to train these new nurse graduates because they were already familiar with the environment. For students who might choose not to work in the same hospital, the facility would also save time and costs in training new nurse graduates who might be likely to leave the facility after a short period of employment.

\subsection{Study limitations}

The pregraduation clinical training program designed for our study was developed to improve the competency of upcoming nurse graduates who were in their final semester at school in Taiwan and to connect the students to potential employers for their first job after graduation. Findings from our study offer an initial step in exploring the effects of this pregraduation training program on promoting pregraduate students' clinical competence from the dual perspective of students and preceptors. However, the study's findings are limited by its design. We utilized a one-group, pretest and posttest design, which presents a reasonable doubt about whether the significant results were solely attributable to the intervention of the pregraduation clinical training program. In addition, one of the meaningful results of this study is that many pregraduates expressed a willingness to continue working in the hospital or unit where they received their practicum; however, the actual retention rate was unknown because of the limitation of the research design. We therefore suggest conducting a longitudinal study with a control group to have a better understanding of the long-term effects of the program on students' willingness and actual choice to continue working in the same hospital or unit where they received their practicum. Qualitative data are also needed to learn more about students' concerns about remaining in and working for the practicing hospital after graduation.

Although this study included three cohorts of pregraduates, the generalizability of the study's findings are limited due to the sampling method and to the sample itself, which involved only pregraduates in the 2-year degree nursing program in our university in Taiwan. We recommend future studies include students in all varieties of undergraduate nursing programs in order to make the generalizability of results more powerful.

\section{Conclusions}

This study demonstrates to healthcare managers, nurse educators, and pregraduate nurses that the transition from student to professional nurse demands professional development and continuing support from hospitals, especially from preceptors. While developing our pregraduation clinical training program, we were careful to assign no more than two preceptors to each student to ensure the pregraduates in our study obtained consistent support that might enhance their successful adjustment to the practice environment and, perhaps, to their future place of employment after graduation. The study results highlighted the significant influence of the preceptors' role on pregraduates' intention to continue working for the hospital or unit where they received their practicum. Therefore, we recommend that hospitals offer formal education to preceptors regarding the value and influence of their roles and to provide training programs about how to mentor pregraduates. More importantly, it is necessary to establish a closer partnership between the academic and practice settings in order to design a more appropriate pregraduation clinical practice program that will improve nursing students' ability to transition to the professional setting after graduation.

\section{Acknowledgement and funding}

We thank for the National Science Council in Taiwan for supporting the funding to conduct the study. 


\section{References}

[1] Nursing Executive Center. Nursing's next generation: Best practices for attracting, training, and retaining new graduates. Washington DC, Advisory Board Company. 2002.

[2] Casey K, Fink R, Krugman M, Propst J. The graduate nurse experience. Journal of Nursing Administration. 2004 ; 34: 303-311. http://dx.doi.org/10.1097/00005110-200406000-00010

[3] Hamilton M. Predicting nursing turnover. 2002. Available from: $\mathrm{http}: / /$ allnurses.com/nursing-activism-healthcare/predicting-nursing-turnover-17937.html

[4] Jones CB. Revisiting nurse turnover costs: Adjusting for inflation. Journal of Nursing Administration. 2008; $38(1)$ : 11-18. PMid:18157000 http://dx.doi.org/10.1097/01.NNA.0000295636.03216.6f

[5] Santucci J. Facilitating the transition into nursing practice: concepts and strategies for mentoring new graduates. Journal for Nurses in Staff Development. 2004; 20(6): 274-284. PMid:15586092 http://dx.doi.org/10.1097/00124645-200411000-00007

[6] Koh L C. Practice-based teaching and nurse education. Nursing Standard. 2002; 16(19): 38-42.

[7] Bradshaw A, Merriman C. Nursing competence 10 years on: fit for practice and purpose yet? Journal of Clinical Nursing. 2007; 7: 1263-1269. http://dx.doi.org/10.1111/j.1365-2702.2007

[8] Rebeschi L, Aronson B. Assessment of nursing student's learning outcomes and employment choice after the implementation of a senior capstone course. International Journal of Nursing Education Scholarship. 2009; 6(1).

http://dx.doi.org/10.2202/1548-923X.1775

[9] Blanzola C, Lindeman R, King M L. Nurse internship pathway to clinical comfort, confidence, and competency. Journal for Nurses in Staff Development. 2004; 20(1): 27-37. PMid:15076126 http://dx.doi.org/10.1097/00124645-200401000-00006

[10] Goode CJ, Lynn MR, Krsek C, Bednash GD. Nurse residency programs: an essential requirement for nursing. Nursing Economic. 2009; 27(3): 142-159. PMid:19558074

[11] Schoessler M, Waldo M. The first 18 months in practice: a developmental transition model for the newly graduated nurse. Journal of Nurses in Staff Development. 2006; 22(2): 47-52. http://dx.doi.org/10.1097/00124645-200603000-00001

[12] del Bueno D. Crisis in critical thinking. Nursing Education Perspectives. 2005; 26(50): 278-282. PMid:16295306

[13] Berknow S, Virkstis K, Stewart B, Conway L. Assessing new graduate nurse performance. Nurse Educator. 2008; 38(11): 468474.

[14] Smith J, Crawford L. Report of findings from the 2001 employers' survey [Internet]. 2002. Available from: https://www.ncsbn.org/RBrief_Employer_053.pdf.

[15] Smith EL, Cronenwett L, Sherwood G. Current assessments of quality and safety education in nursing. Nursing Outlook. 2007; 55(3): 132-137. PMid:17524800 http://dx.doi.org/10.1016/j.outlook.2007.02.005

[16] Kolb DA. Experiential learning: Experience as the source of learning and development. New Jersey: Prentice-Hall. 1984.

[17] Lave J, Wenger E. Situated learning: Legitimate peripheral participation. New York: Cambridge University Press. 2003.

[18] Gillespie M, Paterson BL. Make effective clinical decisions; the situated clinical decision-making framework. Nursing Education Perspectives. 2009; 30(3): 164-170. PMid:19606659

[19] Smith MK. Communities of practice: the encyclopedia of informal education [Internet]. 2009. Available from: http://www.infed.org/biblio/communities_of_practice.htm.

[20] Ericsson KA, IV JW, Ward P. Expert performance in nursing: reviewing research on expertise in nursing within the framework of the expert-performance approach. Advances in Nursing Science. 2011; 30(1): E58-E71.

[21] Zheng R. Effects of situated learning on students' knowledge acquisition: an individual differences perspective. Journal of Educational Computing Research. 2010; 43(4): 467-487. http://dx.doi.org/10.2190/EC.43.4.c

[22] Boxer E, Kluge B. Essential clinical skills for beginning registered nurses. Nurse Education Today. 2000; 20 : $327-335$. PMid:10827104 http://dx.doi.org/10.1054/nedt.1999.0415

[23] Greenberger H, Reches H, Riba S. Do new graduates of registered nursing programs in Israel perceive themselves as technically competent? The Journal of Continuing Education in Nursing. 2005; 36(3): 133-140. PMid:16022033

[24] Fitzgerald LM, Delitto A, Irrgang JJ. Validation of the clinical internship evaluation tool. Physical Therapy. 2007; 87(7): 844-860. http://dx.doi.org/10.2522/ptj.20060054

[25] Glass GV, Peckham PD, Sanders JR. Consequences of failure to meet assumptions underlying the fixed effects analyses of variance and covariance. Review of Educational Research. 1972; 42: 237-288. http://dx.doi.org/10.3102/00346543042003237

[26] Brown B, O'Mara L, Hunsberger M, Love B, Black M, Carpio B, Crooks D, Noesgaard C. Professional confidence in baccalaureate nursing students. Nurse Education in Practice. 2003; 3: 163-170. http://dx.doi.org/10.1016/S1471-5953(02)00111-7 
[27] Crooks D, Carpio B, Brown B, Black M, O’Mara L, Noesgaard C. Development of professional confidence by post diploma baccalaureate nursing students. Nurse Education in Practice. 2005; 5: 360-367. PMid:19040846 http://dx.doi.org/10.1016/j.nepr.2005.05.007

[28] Ulrich B, Krozek C, Early S, Ashlock CH, Africa LM, Carman ML. Improving retention, confidence, and competence of new graduate nurses: Results from a 10-year longitudinal database. Nursing Economic. 2010; 28(6): 363-375. PMid:21291057

[29] Beyea SC, von Reyn LK. Slattery MJ. A nurse residency program for competency development using human patient simulation. Journal for Nurses in Staff Development. 2007; 23(2): 77-82. http://dx.doi.org/10.1097/01.NND.0000266613.16434.05

[30] Burns P, Poster E. Competency development in new registered nurse graduates: Closing the gap between education and practice. The Journal of Continuing Education in Nursing. 2008; 39(2): 67-73. http://dx.doi.org/10.3928/00220124-20080201-03

[31] Oermann MH, Garvin MF. Stresses and challenges for new graduates in hospitals. Nurse Education Today. 2002; $22: 225-230$. http://dx.doi.org/10.1054/nedt.2001.0695

[32] Thomka LA. Graduate nurses' experiences of interactions with professional nursing staff during transition to the professional role. Journal of Continuing Education in Nursing. 2001; 32(1): 15-19. PMid:11868707

[33] Smith ME. From student to practicing nurses: how institutions, managers, and colleagues can ease the transition. American Journal of Nursing. 2007; 107(7): 72A-72D. http://dx.doi.org/10.1097/01.NAJ.0000279276.09970.5e 